\title{
O PROFESSOR E SEUS DESAFIOS NA PANDEMIA - COVID - 19
}

Genésia Alves de Souza

Prof. Ensino fundamental

\section{RESUMO}

O presente artigo tem o objetivo de analisar as vertentes relacionadas ao ponto de vista do professor durante o período inicial da Pandemia do COVID 19. A metodologia utilizada na produção do artigo foi a pesquisa e revisão bibliográfica. A base teórica que fundamentou esta pesquisa foi pautada em publicações, gráficos, documentos publicados em mídias digitais e artigos publicados referentes ao assunto e seu contexto. Juntamente com os estudos realizados pela ONU - Organização das Nações Unidas, Instituto Península, Nóvoa (2020) e Moran (2013). No desenvolvimento do artigo serão apresentadas considerações de subitens relevantes ao tema, assim como a análise de gráficos e dados colhidos durante o período do início pandêmico até os dias atuais (06/2020). Buscando como resultado a expansão do conhecimento sobre o tema.

Palavras-Chave: Professor, Educação, Tecnologia. 


\section{1 - INTRODUÇÃO}

O surgimento de uma doença desconhecida por si só já carrega consigo ansiedade, temor e apreensão. Quando o mundo vê surgir uma pandemia com características tão assustadoras todos os segmentos da sociedade são atingidos de frente e tentam se manter firmes diante de tão grande desafio. Não foi diferente na área educacional mais diretamente, para o professor.

Inicialmente muitos são os profissionais que tiveram uma formação voltada para uma prática pedagógica direcionada ao o ensino tradicional e pouca familiaridade com as mídias digitais. Isso ocorre por falta de disciplinas na formação inicial, continuada ou de treinamento. De acordo com a afirmação de Nóvoa (2020): "Se existe um momento em que a formação continuada dos educadores se faz essencial, este momento é agora. Precisamos discutir e compartilhar uns com os outros e reconstruir nossas aprendizagens". Diante da realidade foram expostos praticamente de um dia para uma noite de frente a um enorme desafio, lecionar para os alunos à distância, preparar conteúdos adaptados às diversas plataformas digitais disponibilizadas pelas escolas e administrar sua vida pessoal agora coexistindo com sua rotina familiar.

Nesse contexto de adequações, inseguranças e despreparo o professor teve sua saúde física e emocional comprometida pela ansiedade, depressão e pela própria doença COVID - 19. Porém é preciso reconhecer o problema, analisar os desafios e implementar soluções, pois o dinamismo da pandemia cobra agilidade, objetividade e sobretudo coerência. Sendo assim organizações públicas e privadas elaboram e medidas para apoio a esses profissionais durante o período pandêmico.

\section{2 - REFERENCIAL TEÓRICO}

O referencial teórico do presente artigo foi estruturado em depoimentos de teóricos da área da educação, profissionais da área de psicologia e em pesquisas de associações educacionais apresentados em quatro tópicos, a saber: formação profissional defasada em relação às novas tecnologias; os desafios do professor diante da pandemia; as consequências da pandemia para o professor; medidas de ajuda e proteção ao professor.

\section{2-1 FORMAÇÃO PROFISSIONAL DEFASADA EM RELAÇÃO ÀS NOVAS TECNOLOGIAS}

A formação inicial dos professores é um tema importante para pesquisadores e acadêmicos na área da Educação. Nota-se que por ser um tema recorrente ele é de extrema importância tanto na análise dos acontecimentos quanto na atuação dos profissionais recém-formados. A formação inicial é parte da condição docente, por isso é preciso se repensar o currículo acadêmico e sua aplicabilidade na vida prática do docente. Especificar as reais necessidades do alunado e a partir daí correlacionar com os conteúdos. 
A formação inicial do professor é necessária e indiscutível, porém o que precisamos considerar também é a continuidade dessa formação assim como sua constante capacitação profissional. Segundo a LDBEN - Lei de Diretrizes e Bases da Educação Nacional, no artigo 62:

$\S 1^{\circ}$ A União, o Distrito Federal, os Estados e os Municipios, em regime de colaboração, deverão promover a formação inicial, a continuada e a capacitação dos profissionais de magistério. (Incluído pela Lei $n^{\circ} 12.056$, de 2009).

As Diretrizes Curriculares Nacionais para a Formação de Professores da Educação Básica preconizam no Art. $2^{\circ}$, inciso VI "o uso de tecnologias da informação e da comunicação e de metodologias, estratégias e materiais de apoio inovadores" (BRASIL, 2002). Nas DCN - Diretrizes Curriculares Nacionais refere também a importância da utilização das tecnologias digitais nos processos de ensino e de aprendizagem. Tais artigos reforçam a importância do tripé: formação inicial, continuada e capacitação. Além do desafio de se estruturar a formação inicial de acordo com os contextos da vida cotidiana e contemporânea, também se deve pensar em preparar os professores para trabalharem com a tecnologia, seus recursos e as novas linguagens decorrentes dela. Pois o mundo está em constante mudança, as crianças de hoje já nasceram em um mundo "tecnológico"; são os nativos digitais. Muitas delas possuem smartfones, tablet's, notebook's e acesso à internet através do wi-fi. Em confirmação a este fato Moran (2013) afirma:

Alunos sem acesso contínuo às redes digitais estão excluídos de uma parte importante da aprendizagem atual: do acesso à informação variada e disponível on-line, da pesquisa rápida em bases de dados, bibliotecas digitais, portais educacionais; da participação em comunidades de interesse, nos debates e publicações on-line, enfim, da variada oferta de serviços digitais. (Moran, 2013, p. 9 e 10)

Sendo assim a didática precisa estar em consonância com os avanços tecnológicos e atualizados aos tempos atuais, onde uma pandemia trouxe à tona o despreparo e a falta de conhecimento de muitos profissionais de ensino em relação à inclusão digital e ensino à distância.

Uma pesquisa realizada pelo CIEB - Centro de Inovação na Educação Brasileira, intitulada “Autoavaliação de Competências Digitais de Professores”, onde mais de 34 mil professores preencheram um questionário que abrange três áreas: pedagógica, cidadania digital e desenvolvimento, concluiu até o momento que a maioria deles está em um nível básico de incorporação de tecnologias. Esse resultado reflete-se agora quando de maneira, repentina e assustadora, a realidade obriga o professor a entender e utilizar as ferramentas disponíveis para manter o aprendizado presente e dinâmico mesmo fora da sala de aula. Para tanto o professor deve se adequar a essa nova realidade. Segundo Moran:

Os docentes podem utilizar os recursos digitais na educação, principalmente a Internet, como apoio para a pesquisa, para a realização de atividades discentes, para a comunicação com os alunos e dos alunos 
entre si, para a integração entre grupos dentro e fora da turma, para publicação de páginas web, blogs, vídeos, para a participação em redes sociais, entre muitas outras possibilidades (Moran, 2013, p. 36-46.).

Consequentemente ele poderá dialogar também com os novos desafios e situações que estão surgindo com o advento da Pandemia do Covid - 19, por exemplo: ter uma atitude aberta ao novo conhecimento tecnológico que futuramente poderá ser levado para a sala de aula e aplicada como um importante apoio à sua prática pedagógica é um deles.

\section{2-2 OS DESAFIOS DO PROFESSOR DIANTE DA PANDEMIA}

Os desafios de uma pandemia surgem sempre de maneira repentina e assustadora; de repente escolas foram fechadas, cidades foram isoladas e professores se viram na difícil missão de dar continuidade no aprendizado dos seus alunos de uma forma diferente daquelas que eles empregavam em sala de aula e distante da sua zona de conforto utilizando as mídias digitais, juntamente com sua vida familiar agora, mais do que nunca, coexistindo com sua vida profissional.

Para Nóvoa (2020), "Nós estamos em uma situação anormal, uma situação de anormalidade e nessa situação excepcional temos que recorrer a todos os instrumentos; as plataformas digitais é um deles." Sendo assim os professores de maneira abrupta, mudaram sua prática pedagógica e buscam se adequar aos novos modos de ensinar.

Neste contexto surge a necessidade de aprender como funcionam as ferramentas digitais disponibilizadas pelas escolas e suas redes de ensino; o que por consequência aumentou o volume e a carga horária de trabalho desse profissional. Os horários de aula na sua maioria são ainda os mesmos de antes da pandemia, porém o trabalho realizado fora dos horários de aulas é ainda maior, pois é preciso planejar, articular conteúdos e desenvolver atividades em um formato diferente do tradicional, denominado por especialistas como "ensino remoto emergencial".

Os professores montaram um novo ambiente de trabalho em suas casas, pois agora estão em distanciamento social com as aulas suspensas. Planejam, gravam e editam as aulas, organizam atividades para disponibilizar em plataformas digitais, preparam material de apoio para o desenvolvimento dinâmico das aulas, gravam áudios no formato de Podcast para consulta dos alunos. Utilizando a tecnologia disponível o professor se aproxima dos alunos, o que afirma Moran:

"O professor pode estar mais próximo do aluno. Pode receber mensagens com dúvidas, pode passar informações complementares para determinados alunos. Pode adaptar a sua aula para o ritmo de cada aluno. Pode procurar ajuda em outros colegas sobre problemas que surgem, novos programas para a sua área de conhecimento. O processo de ensinoaprendizagem pode ganhar assim um dinamismo, inovação e poder de comunicação inusitados. (Nóvoa, 2020) 
Junto a isso ela administra sua rotina domiciliar diária: cuidados extras com a higiene na prevenção à doença COVID - 19 filhos com aulas remotas, companheiro também fazendo home-office, familiares idosos e do grupo de risco que demanda ajuda para a realização de tarefas externas, mensagens em mídias sociais de comunicação contendo informações relacionados ao contexto da administração escolar, dos pais e dos alunos; sendo a maior parte delas enviadas fora do horário habitua de trabalho, entre outros.

Os professores estão reinventando sua didática ao mesmo tempo em que enfrentam as dificuldades inerentes de uma crise pandêmica, o distanciamento social dos alunos e da comunidade escolar, novas modalidades de reuniões em aplicativos que ele não domina, perdas de familiares e amigos para a doença, perda econômica com a redução da carga horária e adequação e o planejamento para um eventual retorno mesmo sabendo das condições estruturais insuficientes do seu local de trabalho.

\section{2-3 AS CONSEQUENCIAS DA PANDEMIA PARA O PROFESSOR}

Subitamente é exigido do professor competências que ele não possui, seja por falta de capacitação, formação continuada ou por acomodação. $O$ advento da utilização das mídias digitais na sala de aula ainda era assunto pouco tratado nas escolas, apesar de ser utilizado diariamente com mais frequência para os alunos e seus familiares.

Muitos estão desorientados, desestimulados e sentem o reflexo disso tudo em sua saúde emocional. Uma pesquisa realizada pelo Instituto Península tem como objetivo analisar os desdobramentos da pandemia atual para os professores. Foram entrevistados de forma direta até agora 7 mil professores, da Educação Infantil ao Ensino Médio das redes particulares, municipais e estaduais. Concluiu-se que $88 \%$ dos professores respondentes nunca haviam dado aula remotamente e o resultado disso foi o aumento da ansiedade desses profissionais. Cerca de 50\% deles sinalizaram preocupação com sua saúde mental. Um total parcial de $75 \%$ dos entrevistados não recebeu nenhum tipo de suporte emocional e ainda teve que administrar o trabalho com questões pessoais, como a morte e a doença de entes queridos por COVID - 19. Para 55\% dos professores um suporte emocional e psicológico seria de grande ajuda durante esse processo de adaptação e incertezas.

Para o professor ao mesmo tempo em que se instituiu a prática do distanciamento social surge a demanda da implementação do ensino digital, que para muitos é inédito, inacessível e impraticável, que gera demandas sociais, econômicas e emocionais dos professores. Muitos tiveram seus contratos de trabalho suspenso ou redução da sua carga horária, por conseguinte redução nos salários, outros já trabalharam em contextos escolares vulneráveis o que gera a preocupação crescente com os alunos. Questões como a intensificação das condições de desigualdade dos alunos; falta de alimentação, segurança, integridade física e suporte emocional.

São tempos de se reinventar, ressignificar e reconstruir, só assim será possível uma aprendizagem efetiva dos alunos. 
A pandemia pode ser considerada como um antecipador de acontecimentos, pois uma mudança dessa dimensão na área educacional demanda tempo, estruturação e capacitação profissional. Para Nóvoa (2020), "Está crise vai nos permitir repensar os novos modelos escolares, os novos modelos educativos". Sendo assim o professor também irá se adequar e encontrar através da sua capacidade de resiliência o caminho para dar continuidade ao processo de ensino e aprendizagem do aluno assim como sua estruturação para administrar as consequências oriundas de um cenário pandêmico. Com ajuda o professor poderá se reinventar e entender que a mudança apesar de abrupta é necessária.

\section{2-4 MEDIDAS DE AJUDA E PROTEÇÃO AO PROFESSOR}

Diante deste contexto e preocupados com os professores, foi criado a Força-Tarefa Internacional para Professores pela Educação 2030, composto por aproximadamente 90 governos, 50 organizações internacionais e agências da ONU - Organização das Nações Unidas, que trabalham para garantir aos professores proteção e reconhecimento durante a pandemia de COVID - 19, com representantes sediados na UNESCO - Organização das Nações Unidas para a Educação, a Ciência e a Cultura em Paris.

Com 165 países sendo afetados diretamente pela doença e mais de 63 milhões de professores de todos os níveis de ensino afastados compulsoriamente devido a quarentena estabelecida nos países atingidos foi preciso estabelecer condições para a continuidade do processo de ensino-aprendizagem para mais de 1,5 bilhões de alunos afastados das escolas.

Em cada localidade as equipes de ensino das escolas particulares e das redes públicas, municipais, estaduais e federais estão trabalhando incansavelmente para permitir a todos os alunos o acesso à educação remota emergencial com o uso das tecnologias digitais disponíveis em cada região e quando não se tem essa tecnologia a educação apesar de prejudicada ainda existem com a entrega de impressos com o conteúdo a ser estudado pelos alunos.

Na tentativa de levar para o aluno um ensino de qualidade e dinâmico ao mesmo tempo deixá-lo seguro e protegido emocionalmente o professor se sobrecarrega, causando estresse, ansiedade, frustação e depressão. De acordo com Telma Vinha, doutora em Educação e professora da UNICAMP - Universidade de Campinas - São Paulo: "A pressão para uma aprendizagem remota sem dar as condições para isso só gera mais ansiedade e pressão para o professor, que demonstra precisar de um suporte emocional e pedagógico". Muitos deles não tiveram formação para tal método de ensino e nem tempo de preparo para os desafios que se instalam. Além do fato que, alguns professores ou seus familiares foram expostos e contaminados pelos vírus circulante da pandemia. Outro aspecto desencadeante de estresse foi a suspensão dos contratos de trabalho e a redução das cargas horárias das aulas.

Para amenizar e contornar essas situações e dar apoio ao professor a Força Tarefa estabeleceu seis normativas básicas de trabalho para execução dos membros 
participantes: $1^{\mathrm{a}}$ - Preservar o emprego e os salários tem como objetivo assegurar que os direitos trabalhistas sejam cumpridos; 2a - Priorizar a saúde, segurança e o bem-estar de professores e estudante, determina que eles tenham apoio socioemocional; $3^{\mathrm{a}}$ - Incluir professores no desenvolvimento de respostas educacionais à COVID - 19, pois os professores são base essencial para o planejamento e elaboração volta do ensino; $4^{\text {a }}$ Fornecer suporte e treinamento profissional adequados, pois a maioria não tem formação ou treinamento para o ensino digital; $5^{\text {a }}$ - Colocar a equidade no centro das respostas da educação à crise, dar apoio e flexibilizar medidas para regiões de vulnerabilidade social e $6^{\mathrm{a}}$ - Incluir os professores nas respostas de ajuda, busca apoio financeiro e para suprir necessidade de países pobres e a qualificação profissional.

Também com o propósito de auxiliar os professores neste momento de apreensão e incertezas, foi criada por um grupo de professores a plataforma digital EDUCOVID Educadores na COVID - 19, que tem por objetivo a coleta de informações sobre as demandas dos professores, análise dos dados, esclarecimento das dúvidas por especialistas e apresentação de uma curadoria de materiais de apoio que são enviados por e-mail. O psicanalista Christian Dunker - do Instituto de Psicologia da USPUniversidade de São Paulo afirma em um vídeo disponibilizado para o apoio aos professores que: "A linguagem é diferente, o tempo é diferente, o escopo é diferente e nós também estamos diferentes nessa situação. A primeira regra é aceitar e acolher essa diferença e começar a trabalhar a partir dela".

Com uma reconhecida capacidade de adaptação ao seu contexto de trabalho o professor está mais uma vez sendo desafiado à adequação, forçado a desenvolver habilidades de acordo com a demanda situacional. Porém a ajuda para isso já está sendo elaborada e posta em prática para enfrentar mais esse momento marcante da história. 


\section{BIBLIOGRAFIA}

Após seis semanas de isolamento os professores não receberam suporte adequado para ensinar a distância e nem suporte emocional. Publicado em 02 de jun. de 2020. Disponível em: $<$ https://institutopeninsula.org.br/apos-seis-semanas-de-isolamentoprofessores-brasileiros -nao-receberam-suporte-suficiente-para-ensinar-a-distancianem-suporte-emocional-das-escolas/>. Acesso em 20 jun. 2020.

Casatti, Denise. Um guia para sobreviver à pandemia do ensino remoto. Publicado em 07 de mai. de 2020. Disponível em:<http://www.saocarlos.usp.br/um-guia-parasobreviver-a-pandemia-do-ensino-remoto/>. Acesso em 21 de jun. 2020.

Educação Bahia. Formação Continuada - Aula Magna António Nóvoa. 2020. Disponível em: $<$ https: $/ /$ www.youtube.com $/$ watch? $\mathrm{v}=7 \mathrm{kSPWa} 5 \mathrm{Nieo}>$. Acesso em 21 de jun. 2020.

Educadores na Covid-19. Disponível em: $<$ https://educovid.org/>. Acesso em 21 de jun. 2020

Estimular as Competências Digitais dos Professores reforça o Ensino na Infância. Publicado em 08 out. 2019. Disponível em: $<$ https://cieb.net.br/estimular-ascompetencias-digitais-dos-professores-reforca-o-ensino-na-infancia/>. Acesso em 14 jun. 2020.

Força-tarefa para Professores pede apoio a 63 milhões de professores afetados pela crise da COVID-19 - Publicado em 27 de abr. de 2020. Disponível em: < https://pt.unesco.org/news/forca-tarefa-professores-pede-apoio-63-milhoesprofessores-afetados-pela-crise-da-covid19\#: : text $=\mathrm{A} \% 20$ For $\% \mathrm{C} 3 \% \mathrm{~A} 7 \mathrm{a} \% 2$ Dtarefa $\% 20$ Internacional $\% 20$ para, sociedade $\% 20$ civil $\% 2 \mathrm{C} \% 20 \mathrm{da} \% 20$ profiss $\% \mathrm{C} 3 \% \mathrm{~A} 30 \% 20 \mathrm{de}$. Acesso em 13 de jun. de 2020.

Lei de Diretrizes e Bases da Educação Nacional n 9394/96 de 20 de dezembro de 1996. Brasília: MEC, 1996. Disponível em:< http://portal.mec.gov.br/seesp/arqu ivos/pdf/lei9394_ldbn1.pdf $>$. Acesso em 13 jun. 2020.

Libãneo, J. C. Adeus Professor, Adeus Professora? : Novas exigências educacionais e profissão docente. $4^{\mathrm{a}}$ ed. São Paulo: Cortez, 2000.

Moran, José Manuel. A integração das tecnologias na educação. A Educação que desejamos: novos desafios e como chegar lá. $2^{\circ}$ ed. Campinas, São Paulo. Papirus, 2007. Disponível em: $<$ https://books.google.com.br/books?Id=PiZe8ahPcD8C\&printsec=frontcover $\& \mathrm{hl}=\mathrm{pt}-\mathrm{BR} \# \mathrm{v}=$ onepage $\& \mathrm{q} \& \mathrm{f}=$ false $>$. Acesso em 21 jun. 2020.

Moran, José Manuel. Novas Tecnologias e o Reencantamento do Mundo. Publicado na Revista Tecnologia Educacional. Rio de Janeiro, vol. 23, n.126, setembro-outubro 1995, p. 24-26. Disponível em: $<$ http://www.eca.usp.br/prof/moran/site/textos/tecnologias educacao /novtec.pdf $>$. Acesso em 14 de jun. de 2020

Rede global de governos e organizações pede apoio aos profissionais de educação durante pandemia. Publicado em 09 de jun. de 2020. Disponível em: < https://nacoesunidas.org/rede-global-de-governos-e-organizacoes-pede-apoio-aprofissionais-de-educacao-durante-pandemia/ > . Acesso em 14 de jun. 2020

Sentimento e percepção dos professores brasileiros nos diferentes estágios do coronavírus. Publicado em 31 de mar. de 2020. Disponível em: $<$ https://www.ins titutopeninsula.org.br/pesquisa-sentimento-e-percepcao-dos-professores-nosdiferentes-estagios-do-coronavirus-no-brasil/>. Acesso em 20 de jun. 2020. 